\title{
SPECIAL THEME
}

\section{AT THE FRONTIERS OF PRACTICE AND THEORY Editorial}

\section{INTRODUCTION}

To anyone active in higher education, whether as practitioner or as researcher, one salient feature of this field is its relative youth. In Europe, the origins of study of higher education as a policy area can be traced back some 30 years - to the early 1960s and to the very real problems which governments and administrations faced with the pressure to expand places and establishments in the nation's provision of higher education. Its youth is, as we have suggested, relative - relative, that is, to some of the component disciplines such as political science and public administration, economics and sociology. Depending on the country concerned, one may trace the origins of the two former areas to early 17th-century Sweden (the first Chair of Political Science was set up in the University of Uppsala during the reign (1611-1632) ] of Gustavus II Adolphus and to the Cameralist school of Halle in the later part of that same century; the latter two may be traced to 18th-century Scotland and 19th-century France in the persons of Adan Smith and Auguste Comte. But the study of higher education is distinguished by two other features which, though present in its contributing disciplines, nevertheless tended to emerge early on in this area.

\section{LINKS BETWEEN PRACTICE AND THEORY}

The first is the close linkage with issues of a current and practical nature. Here, though it is probably indelicate to say so, one may detect certain similarities with that other area which is sometimes seen as running partly in parallel and partly overlapping namely comparative education. As with comparative education, so with higher education; the first (and, some still claim, its major) function was to examine other systems and practices, the better to highlight one's own. As an alternative possibility, its function was to find out just how far provision and practice, taken for granted in one setting, possessed commonalties or could be said to constitute exceptionalities when placed against others. Far-fetched though it may appear, one can observe a certain similarity of approach in the British context, for example between the pioneering work in the 19th century of Matthew Arnold, and later Michael Sadler and the Robbins Report. Both were concerned with immediate issues: the former two with improving the quality of teaching, the latter with seeking other models to give insight into the various options which lay before British higher education, then on the threshold of massive growth.

The second outstanding feature of policy studies in higher education has been, almost from the first, their comparative nature. This has been sustained within the European context by such bodies as the Organization for Economic Cooperation and Development in the United States in conjunction with Europe by the International Council for Educational Development of New York. In a broader setting still, the contribution of Unesco may be seen as having been substantial.

\section{NEW DEVELOPMENTS IN THE RESEARCH COMMUNITY}

Within this framework, one can note a number of developments, first as regards the relationship between comparative and national studies and second, as regards its disciplinary composition. Over the ensuing three decades, the size of the scholarly community in higher education has grown, both in proportion to the size of its object of enquiry and in proportion to public involvement and interest in the overall enterprise. Yet this growth of the scholarly community - whether those engaged in the study of higher education as the major focus of their research or (as is more often the case) as an area of application arising from their substantive interests - has not been achieved without a certain tension between what one might term the 'comparative' or 'international' dimension and the 'national system' approach. It remains, by and large, a fact that the bulk of empirical work has as its prime focus higher education within one nation and even a particular sector within that nation's provision - the university as opposed to the non-university sector, community colleges as opposed to the research universities in the United States. Such a feature is not particularly astounding. Research councils and foundations tend to give priority to scholars working in the countries where those foundations are themselves located and, though there are notable exceptions, the general rule is that the holders of the purse, whether public or private, will show a natural concern with their own systems of higher education. Comparative studies tend, though by no means exclusively so, to be the object of international bodies and organizations. There is, too, a certain suspicion among trustees or national administrators that the wider the study, the less rigorous or less applicable the findings which may result or the less relevant they will be for the funding nation. Such considerations have shaped the higher education community and certainly contributed to its expansion, but within the national setting and most particularly in the course of the 1970s. There are signs now that national research groupings are turning their attention outwards, and extending their areas of interest to include a cross-national perspective though often within the same region. In short, one sees a species of 
capillary action flowing from beneath and forming into research networks with their base at the cutting edge of research and teaching.

\section{THE CUTTING EDGE}

The cutting edge can be considered in two ways. It can be seen as the most recent and most challenging theoretical work, bringing order, light and understanding to what hitherto appeared chaotic or unexplained or both. It can also be seen as the point at which such knowledge is not merely generated and made more profound, but is also transmitted and handed down to the next generation of researchers, teachers and students. It is at this point that, by its very nature, the study of higher education finds itself in the greatest jeopardy. Its delicate condition arises from the nature of its constituency - that is, those who both commission and consume the fruit of its research and thought. As I have intimated earlier, in the main this has tended to be governments, administration (either national, local or institutional) or the world of international civil servants and, in those rare programmes involved in teaching, their students tend equally to come from similar backgrounds. They are being trained by researchers less to do research - though obviously this forms an important element - than to have a better managerial grasp of the various levels of the system they will administer in the future. Teaching in this area is, essentially, involved once again in the practical and managerial aspects of the higher education system as well as enabling administration to have a better understanding of the implications of the latest work, to be able to incorporate it, where possible, into planning and to be able to identify areas where future work nnay be carried out either by the institution or ministry in which they are active or, delegated outside in contracts, by those who have taught them. Higher education research exists, then, in a remarkably closed community, the other characteristic of which may be compared to what in cybernetics is sometimes known as a 'closed cycle' system.

If this is the situation at national level, the same condition is present perhaps in a form even more exaggerated, at the level of international agencies where the research community generates knowledge to be consumed mainly within them; or as a second possibility to be transmitted as part of a two-stage information flow out to the world of national administration; or finally to those working on similar problems as consultants elsewhere. Again, with one or two exceptions, the world of international agencies may have governments as its students, but as far as having students who will themselves go on to teach the study of higher education they are, alas, not dissimilar to the genetic condition of the mule.

Whether one wishes to interpret this situation as a form of fragility, or simply as a stage in the evolution of what may be seen as a 'problématique' on the way to becoming a coherent field of study, is clearly a matter of personal opinion and of the particular disciplinary perspective out of which one works and from which one views matters. But it is certain that another outstanding feature of higher education as a field of enquiry is that researchers and contributors in all probability outnumber their students, save in the United States or Canada.

There are, however, other consequences of the 'closed cycle' relationship between researchers and consumers of higher education research. One of these has been the fact that the large-scale research agenda has often been determined less by the research community than by government or by commissioning agencies, national or international. While this may have the advantage of ensuring that the contribution of research remains closely aligned, if not with policy then at least with the exploration of options leading to policy formulation, it has also meant that the development of a long-term research agenda by the research community itself has largely been absent. This is not to say, of course, that excellent work has not been done, nor that large scale research of an international nature concerned with the testing and generation of theory is entirely lacking. But it has tended, until recently, to be relatively rare.

\section{COMMUNICATING RESEARCH AND SPREADING NEWS}

Finally, from the research community's standpoint, there is the question of communicating research findings. Here, too, the situation is changing and the development of journals specifically devoted to this area has been particularly rapid over the past decade and a half. One may identify three types of journal. The first and most recent variation is the mass circulation, professional journal, designed to appeal to all elements of higher education from institutional news through to science policy, from the doings of well-known individuals through to events - some that are tragic, some that are bizarre and others that are downright hilarious - that affect institutions or systems. Journals of this ilk combine journalism with scholarship. The second type represents the interests and views of a particular group within the higher education constituency: university presidents, admissions officers, university administrators. Publications in this category turn around the technical and focused professional concerns of their constituency, while combining them with the views of well-known practitioners. The third type of publication corresponds more closely to the established format of academic reviews. It is taken up with reporting research findings, is often the emanation of particular research institutes or brings together individuals active in research on higher education. Such publications are concerned primarily with building up the knowledge base of higher education and its theoretical perspectives as opposed to the exchange of news or views.

Higher Education Policy has as its prime goal the combination of the objectives of the third group of publications in conjunction with features usually found in the second. Essentially, it caters for the views and practical concerns of university presidents and administrators while bringing those concerns together with the work of the research community. Practice and theory are set in the same forum hopefully in dialogue. Naturally, such ambitions are not products of a moment's inspired thought but are part of a service which the International Association of Universities provides to the higher education community in general and to its membership in particular; one of the prime services must lie, surely, in that cross-fertilization of ideas which comes from the synergy of the latest research dealing with current issues. From the standpoint of the research community, however, it also provides a vehicle in which theoretical analyses are put to the test in the light of their potential for application.

In this issue, we have sought to make a balance between both concerns. The articles by Lillis, El-Sayyad and Venkatasubramanian can be seen as falling into the practical side of that continuum which runs throughout higher education 
policy studies. Each in its own manner is concerned with down-to-earth affairs: the factors to be taken into account when deciding whether a university should be created, the type of service which one university may provide in its region and the trends which have emerged over the past two to three years in the higher education system of one country. Set in contrast to this are the contributions from Henkel, Teichler, Eicher, Kogan and Häryrynen and his colleagues. Their concern lies precisely in analysing where the 'cutting edge' lies - at least in the Western European context - with respect to such issues as the relationship of higher education to work, the repercussions of the financial crisis which, if not unique to Western Europe, may have some specific characteristics less emphasized elsewhere.

These articles are part of a broader exercise which has been carried out over the past two years by the Consortium of Higher Education Researchers (CHER) which was founded in 1988. It brings together individual academics from most of the European countries interested primarily in developing comparative policy analysis in higher education. Higher Education Policy is more than happy to provide an opportunity for such ideas, first developed within a relatively limited group, to be brought before the community of international scholarship.

Finally, we have the first in a series of regular articles by John Hayman which will deal with the impact of technological change on higher education. Hayman, as the readers of a previous volume of Higher Education Policy (vol. 2 . no. 4) will know, combines the dual expertise of being a specialist in computer applications and a policy analyst. As such, he represents yet another example of the way in which independent disciplines brought to focus on the area of higher education enrich both the nature of the debate taking place there while extending the range of disciplinary perspectives from which the field of higher education analysis ultimately benefits.

Guy Neave 